\title{
Evaluation of CoBlast Coated Titanium Alloy as Proton Exchange Membrane Fuel Cell Bipolar Plates
}

\author{
Atinuke M. Oladoye, ${ }^{1}$ James G. Carton, ${ }^{2}$ and Abdul G. Olabi ${ }^{3}$ \\ ${ }^{1}$ School of Mechanical \& Manufacturing Engineering, Dublin City University, Dublin 9, Ireland \\ ${ }^{2}$ EnBio Ltd., NOVA, University College Dublin (UCD), Belfield Innovation Park, Dublin 4, Ireland \\ ${ }^{3}$ School of Engineering, University of the West of Scotland, Paisley PA1 2BE, UK \\ Correspondence should be addressed to Atinuke M. Oladoye; atinuke.oladoye2@mail.dcu.ie
}

Received 27 January 2014; Revised 28 April 2014; Accepted 28 April 2014; Published 28 May 2014

Academic Editor: Paolo Fornasiero

Copyright (C) 2014 Atinuke M. Oladoye et al. This is an open access article distributed under the Creative Commons Attribution License, which permits unrestricted use, distribution, and reproduction in any medium, provided the original work is properly cited.

\begin{abstract}
We investigated the potential of graphite based coatings deposited on titanium $\mathrm{V}$ alloy by a low-cost powder based process for bipolar plate application. The coatings which were deposited from a mixture of graphite and alumina powders at ambient temperature, pressure of $90 \mathrm{psi}$, and speed of $20 \mathrm{~mm}$ were characterised and electrochemically polarised in $0.5 \mathrm{M} \mathrm{H}_{2} \mathrm{SO}_{4}+2 \mathrm{ppm} \mathrm{HF}$ bubbled with air and hydrogen gas to depict the cathode and anode PEM fuel cell environment, respectively. Surface conductivity and water contact angles were also evaluated. Corrosion current in the $1 \mu \mathrm{A} / \mathrm{cm}^{2}$ range in both cathodic and anodic environment at room temperature and showed negligible influence on the electrochemical behaviour of the bare alloy. Similar performance, which was attributed to the discontinuities in the coatings, was also observed when polarised at $0.6 \mathrm{~V}$ and $-0.1 \mathrm{~V}$ with air and hydrogen bubbling at $70^{\circ} \mathrm{C}$ respectively. At $140 \mathrm{~N} / \mathrm{cm}^{2}$, the coated alloy exhibited contact resistance of $45.70 \mathrm{~m} \Omega \cdot \mathrm{cm}^{2}$ which was lower than that of the bare alloy $\left(66.50 \mathrm{~m} \Omega \cdot \mathrm{cm}^{2}\right)$ but twice that of graphite $\left(21.29 \mathrm{~m} \Omega \cdot \mathrm{cm}^{2}\right)$. Similarly, the wettability test indicated that the coated layer exhibited higher contact angle of $99.63^{\circ}$ than that of the bare alloy $\left(66.32^{\circ}\right)$. Over all, these results indicated need for improvement in the coating process to achieve a continuous layer.
\end{abstract}

\section{Introduction}

Proton exchange membrane (PEM) fuel cells as shown in Figure 1 are energy conversion devices that generate clean electrical energy from the electrochemical reaction between hydrogen and oxygen via an electrocatalyst and a solid polymer membrane at temperatures between $60^{\circ} \mathrm{C}$ and $80^{\circ} \mathrm{C}$. They are increasingly being targeted for transportation and stationary and portable power generation due to their low operating temperature, high power density, quick start-up capacity, and rapid response to varying load advantages over other types of fuel cells [1-4]. Nonetheless, the widespread utilisation of these clean power sources for such applications is limited by a number of challenges including cost and durability of PEM fuel cell stack components.

A PEM fuel cell stack is made up of several single cells connected in series. Each single cell consists of a thin layered membrane electrode assembly (MEA) sandwiched between two bipolar plates as depicted in Figure 1. The MEA, which is composed of the gas diffusion layer (GDL), the catalyst layer, and the proton exchange membrane (PEM), performs critical roles that control the transport of protons, electrons, and reactant gases from one electrode to the other. The bipolar plates, on the other hand, electrically connect adjacent cells in the stack, facilitate uniform distribution of reactant gases over the entire active electrode area, and provide pathway for removal and management of by-products, as well as mechanically supporting the MEA $[5,6]$. To effectively perform these roles, materials for bipolar plate application are required to be impermeable to gas, corrosion resistant, and chemically and mechanically stable as well as possessing high electrical and thermal conductivity.

Bipolar plates are the most repetitive components in PEM fuel cell stacks accounting for a significant proportion of the cost and weight of the stack. Thus, reducing the cost of these plates is considered vital to commercialization of 


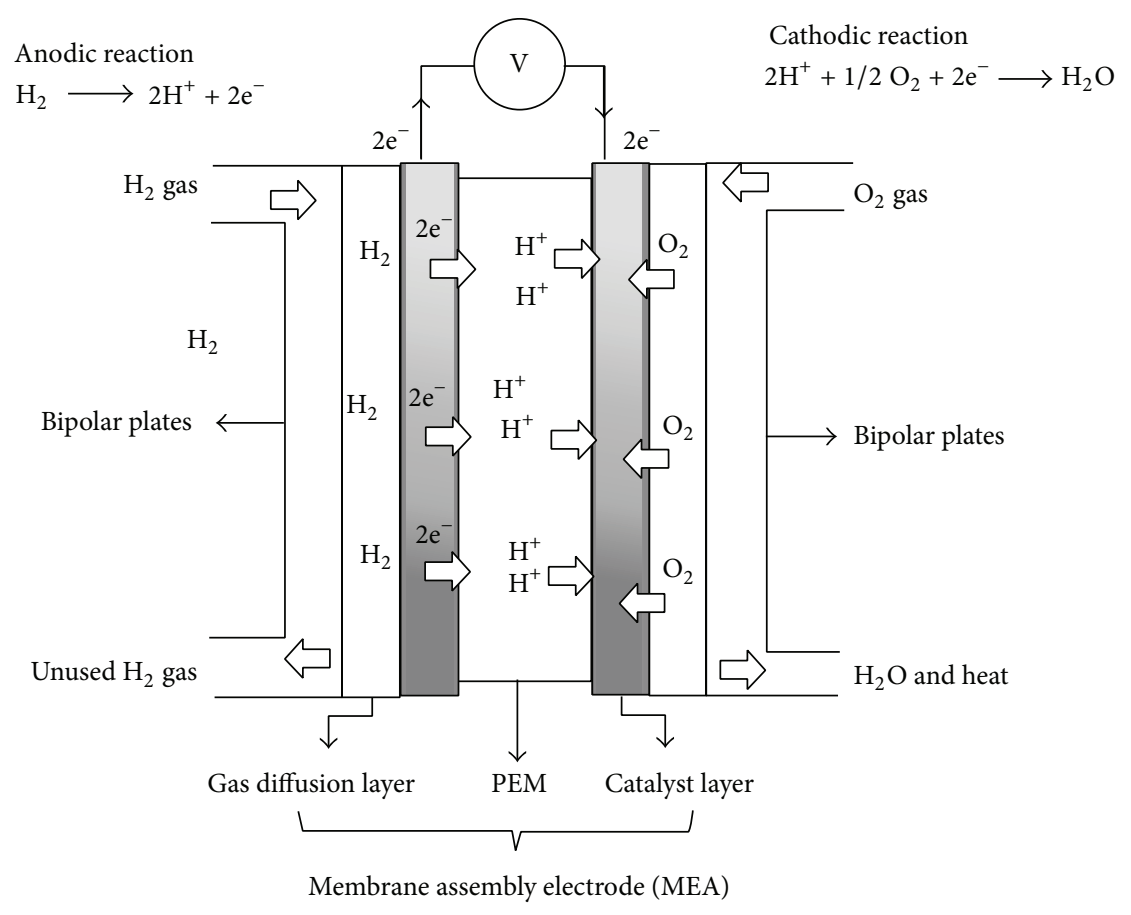

FIgUre 1: Schematic of a single cell PEM fuel cell.

PEM fuel cells. Earlier reports indicated that bipolar plates accounted for about $35-45 \%$ and $60-80 \%$ of the cost and weight, respectively $[7,8]$, but it has recently been shown that, for a $80 \mathrm{KW}$ net automotive PEM fuel cell stack consisting of 369 single cells and 740 bipolar plates, the cost contribution of bipolar plates to that of the total stack can be further reduced with replacement of conventional materials [9]. Bipolar plates are traditionally fabricated from nonporous graphite due to its high corrosion resistance and high surface conductivity in the warm, acidic, and humid PEM fuel cell environment. Conversely, graphite is brittle and has to be made several millimetres thick via resin impregnation to prevent gas leakage. In addition, the processing and machining cost associated with graphite bipolar plates is too enormous for mass production consideration. Thus, alternative materials such as metals and carbon based composites are under investigation for replacement of graphite bipolar plate.

Metals offer many advantages over carbon based composite and graphite as they possess high mechanical strength and can be made thinner to achieve higher power density than that obtainable with thick graphite plates. Metals are also impermeable to gases and are better conductors of heat and electricity as well as being amendable to low-cost production process like stamping and hydroforming. Nonetheless, metals are susceptible to corrosion attack in PEM fuel cell environments and exhibit low contact resistance with the GDL. Therefore, corrosion resistant and conductive coatings and surface treatments that meet the $<1 \mu \mathrm{A} / \mathrm{cm}^{2}$ corrosion current and $<20 \Omega \cdot \mathrm{cm}^{2}$ contact resistance at compaction pressure of $140 \mathrm{~N} / \mathrm{cm}^{2}$ targets set by the United State Department of Energy (US DOE) are recommended for metals to be viable as bipolar plate material $[6,10]$.
Among the metals under consideration for bipolar plate application, titanium (Ti) and its alloys stand out as choice material for portable devices where cost requirements are not too stringent. Ti possesses a high strength to weight ratio and exhibits passivation behaviour in most aqueous environments due to the formation of a thin layered surface oxide [11]. Nonetheless, Ti corrodes when exposed to the harsh operating conditions of PEM fuel cells producing metallic ions which could be trapped in the membrane and, consequently, reduce its conductivity and efficiency. The semiconductive nature of the surface oxide increases interfacial ohmic losses between the bipolar plates and the GDL, thereby promoting conversion of chemical energy to thermal energy rather than the desired electrical energy.

Researchers at Loughborough University, UK, were probably the first to investigate the performance of titanium bipolar plates. In their study, they compared the single cell performance of titanium bipolar plates with that of poco graphite, 316 and 310 stainless steel bipolar plates [3]. Their results showed that the interfacial resistivity of $\mathrm{Ti}$ exhibited about eight-fold increase from the initial $32 \mathrm{~m} \Omega \cdot \mathrm{cm}^{2}$ at $220 \mathrm{~N} / \mathrm{cm}^{2}$ due to the growth of the surface oxide at the end of 1300 hours of polarisation. Consequently, the cell suffered significant power degradation compared to cells with bipolar plates fabricated from the other materials. The plates were thereafter coated with FC5 by a proprietary process and investigated in simulated and real PEMFC environment [12]. The results revealed that the coated plates had comparable ICR with graphite because the coatings prevented the oxidation of the substrate. Therefore, the single cell performance of the coated plates was significantly improved over that of uncoated 316 stainless steel plates and 
no contamination of the membrane due to metallic ions was observed.

Recently, few studies have attempted to explain the corrosion phenomena of $\mathrm{Ti}$ and its alloys in PEM fuel cell environments. Soma et al. [13] found that the air-formed surface oxide on Ti becomes unstable when exposed to PEM fuel cell anodic conditions thereby resulting in high anodic currents at the inception of polarisation. This behaviour of $\mathrm{Ti}$ in anodic conditions was attributed to the low applied potential of $-0.1 \mathrm{~V}$. The preexisting passive layer however rapidly dissolves and gives way to a newly formed oxide layer which cathodically protects the metal. Conversely, the surface oxide was reported to be stable at the cathode but could not totally prevent dissolution. These findings were consistent with that of Wang and Northwood [14] but they added that the applied potential at the cathode dictated the behaviour of Ti (II) alloy in PEM fuel cell environment rather than its passivation characteristics. Therefore, Ti would still corrode at the cathode despite the formation of stable surface oxide promoted by the rich oxygen environment while the presence of hydrogen coupled with a low polarisation potential partially protects Ti from corrosion at the anode. Based on the evaluation of metallic ion leached into the solution after ten hours of polarisation, they concluded that Ti electrodes would lead to unacceptable deterioration of stack output. Hence, surface modification would be needed to enhance performance of $\mathrm{Ti}$ and its alloys in PEM fuel cell environments.

Surface coatings and treatments for metallic bipolar plates are basically divided into metal and carbon base coatings $[8,10]$. For $\mathrm{Ti}$, precious metal coatings and nitrides have been widely investigated. Wang et al. [15] examined the performance of platinum coated and iridium oxide sintered Ti plates in a $25 \mathrm{~cm}^{2}$ active area single cell operated at $50^{\circ} \mathrm{C}$ and discovered that the coated plates exhibited better performance than the uncoated plates but recorded a lower output than graphite plates. Thus, in terms of increasing cell voltage output, the plates were ranked: graphite $>$ platinum $>$ iridium oxide $>$ bare Ti plates. However, the cost of the coatings amongst other factors prohibited further studies and as a result the authors adopted a $2.5 \mu \mathrm{m}$ thick gold coating which was about $90 \%$ cheaper than the former coatings. The gold coatings were deposited on Ti plates by a proprietary process and tested under varying cell operating temperature (40$60^{\circ} \mathrm{C}$ ) and membrane humidifier temperatures $\left(70-90^{\circ} \mathrm{C}\right)$ [16]. Their results indicated that gold coated plates showed superior performance to graphite plates at high membrane humidifier temperatures between $80^{\circ} \mathrm{C}$ and $90^{\circ} \mathrm{C}$ at the operating temperatures with the best performance at $40^{\circ} \mathrm{C}$. However, at lower membrane humidifier temperatures (70$80^{\circ} \mathrm{C}$ ), an opposite trend was observed due to dehydration of the membrane. Similarly, Jung et al. $[17,18]$ demonstrated that $\mathrm{Ti}$ coated with platinum and gold via electrochemical deposition and sputtering process, respectively, prevented the oxidation of the base metals during operation in a $5 \mathrm{~cm}^{2}$ active area single cell operated at $75^{\circ} \mathrm{C}$. Accordingly, stable and improved performance was observed for cells with coated bipolar plates while cells with uncoated plates suffered severe power degradation.
Zhang et al. [19] evaluated the in situ and ex situ performance of TiN coatings deposited by a PVD based process on Ti bipolar plates. The ex situ test revealed that the coatings retarded the corrosion rate of the substrate and reduced its ICR. In the same manner, the in situ test indicated that the voltage output of the cell with the coated plates exceeded that with the uncoated plates and achieved a maximum power density of $0.68 \mathrm{~W} / \mathrm{cm}^{2}$ with a corresponding current density of $1600 \mathrm{~mA} / \mathrm{cm}^{2}$ at $0.65 \mathrm{~V}$. The plates also demonstrated good durability when tested for over 1000 hours showing minimal deterioration in cell output due to membrane contamination by Ti ion especially at the cathode. Based on these results, the authors investigated the stack performance of the TiN coated Ti plates and reported that the stack exhibited about $57 \%$ of the power density observed with the single cell at the same voltage [20]. The lower performance of the stack compared with the single cell was attributed to variation in flow field designs and flow channel parameters of the bipolar plates utilised in the stack. Nonetheless, the study showed that high gravimetric power density $(1353 \mathrm{~W} / \mathrm{Kg})$ can be achieved with TiN/Ti bipolar plates.

Modification of Ti by plasma immersion ion implantation (PII) at high temperature $\left(\sim 370^{\circ} \mathrm{C}\right)$ has also been reported to enhance the corrosion resistance of $\mathrm{Ti}$ in simulated PEM fuel cell environment while the same process conducted at temperatures lower than $100^{\circ} \mathrm{C}$ deteriorated the performance of the substrate [21]. The difference in the inhibitive properties of both samples was attributed to the thickness of the titanium oxynitride surface layer formed during the implantation process. In contrast, modification of $\mathrm{Ti}$ by plasma nitriding at $900^{\circ} \mathrm{C}$ could not adequately protect the base metal from corrosion when exposed to $0.5 \mathrm{M} \mathrm{H}_{2} \mathrm{SO}_{4}+5 \mathrm{ppm} \mathrm{HF}$ but reduced its ICR by $60 \%$ at $220 \mathrm{~N} / \mathrm{cm}^{2}$ [22].

Carbon based coatings, unlike metal based coatings, are seldom reported for corrosion protection of Ti in the PEMFC environment. Show et al. $[23,24]$ reported that the ex situ contact resistance and single cell performance of amorphous carbon coated Ti bipolar plates were dependent on the deposition temperature which ranged from room temperature to $600^{\circ} \mathrm{C}$. The surface conductivity and cell output of the coated plates increased as deposition temperature increased. In particular, the ICR values decreased from $400 \mathrm{~m} \Omega \cdot \mathrm{cm}^{2}$ at ambient temperature to $2.5 \mathrm{~m} \Omega \mathrm{cm}^{2}$ at $600^{\circ} \mathrm{C}$. Accordingly, the cell output of the $600^{\circ} \mathrm{C}$ coated bipolar plate exceeded that of the room temperature coated plates by $80 \%$ and that of the uncoated plates by approximately $39 \%$. In recent times, Wang et al. [25] have also demonstrated that boron doped diamond coatings can significantly improve anticorrosion properties of titanium grade (II) alloy exposed to $0.5 \mathrm{M} \mathrm{H}_{2} \mathrm{SO}_{4}+2 \mathrm{ppm} \mathrm{HF}$ at $80^{\circ} \mathrm{C}$.

From the foregoing literature review, it is noted that a number of vacuum or plasma based surface modification processes have been reported for improving the corrosion and decreasing ICR of Ti plates. Coatings from vacuum related processes are well known to contain pores which often compromise coating integrity. Besides, these processes require specialist equipment and expensive gases which can further increase production cost. In this study, we propose a 
low-cost and scalable surface enhancement process based on the principle of microblasting for improving the performance of Ti in PEM fuel cell environments. The process named CoBlast deposits coatings from the bombardment of a mixed stream of powder particles entrained in a compressed air jet at ambient temperature and atmospheric pressure on reactive metallic substrates. A key attractive feature of the process is its ability to produce strongly adhered coatings within a relatively short time with low energy input [26-28]. Considering these advantages of the process and the fact that graphite is an ideal material for corrosion protection and surface conductivity in PEM fuel cell environments, it could be possible to reduce production cost and improve durability of bipolar plates using CoBlast modified surfaces. Hence, this study is aimed at investigating the suitability of graphite coatings deposited by CoBlast on Ti alloy for bipolar plate application.

\section{Experimental Details}

2.1. Deposition Process. Titanium grade (V) coupons of dimension $150 \mathrm{~mm} \times 150 \mathrm{~mm} \times 1 \mathrm{~mm}$ were selected as substrate for the present study. The coating powder consisted of flaky graphite powder (grade: microfyne; Southwestern Graphite, USA) and alumina powder (particles size: $50 \mu \mathrm{m}$; Comco Inc., CA, USA) mixed in a predefined ratio in a laboratory tubular for fifteen minutes. Alumina facilitates removal of the surface oxide in order for the coating powder (graphite) to be impregnated onto the metal surface by tribochemical bonding and mechanical interlocking [26-28]. The substrates were thoroughly wiped with isopropanol, airdried and arranged on the platform of the CoBlast coating equipment at a working distance of $\sim 20 \mathrm{~mm}$ from the CoBlast nozzle head. The metal surfaces were thereafter modified by blasting with streams of the processed powder fed through the CoBlast nozzle at $90 \mathrm{psi}$ and speed of $12 \mathrm{~mm} / \mathrm{s}$. The blasting process was continued in the perpendicular direction until the entire surface was covered. After coating, the modified surfaces were blasted with dry air to remove loosely adhered material and wiped with isopropanol. In this study, the process parameters were based on those earlier reported for deposition of bioceramics by the same process [26].

2.2. Surface Characterisation. The modified and bare samples were characterised using X-ray diffraction (XRD), X-ray photoelectron spectroscopy (XPS), scanning electron microscope (SEM)/energy-dispersive X-ray spectroscope (EDX), and contact angle goniometer. XRD analysis was conducted with a D8 Advance Bruker X-ray diffractometer with $\mathrm{CuK} \alpha$ radiation anode source operated at accelerating voltage of $40 \mathrm{KV}$ and beam current of $40 \mathrm{~mA}$ in the $20^{\circ}-80^{\circ}$ range. Glancing XRD technique at incidence angle of $1^{\circ}$ was used for the modified sample while locked coupled scan was employed for the bare sample. Narrow region scans of C1s, Al2p, Ti2p, and O1s of the samples to a depth of $10 \mathrm{~nm}$ were obtained with a Thermo ESCALAB 250Xi XPS model with AlK $\alpha$ X-ray source $(1486.6 \mathrm{eV})$ at constant pass energy of $20 \mathrm{eV}$. All data were acquired after 60 seconds of argon ion sputtering and referenced to hydrocarbon $\mathrm{Cls}$ at $284.5 \mathrm{eV}$ binding energy. Surface morphology and cross-sectional view of the samples were examined with a bench top ZEISS EVOLS 15 SEM operated at $15 \mathrm{KV}$ accelerating voltage in the secondary and backscattered electron mode while compositional analysis of the samples was obtained using EDX (INCA, Oxford instruments). Water contact angle measurements were conducted with a First Ten Angstroms FTA200 (Portsmouth, VA, USA) contact angle analyser by dropping a predefined volume of distilled water on the surfaces of the sample via a computer controlled syringe pump. Images of water drop on the surface of the samples were taken and analysed with the FTA32 Video 2.0 software. Mean values for four measurements are reported.

2.3. Contact Resistance Measurement. Interfacial contact resistance (ICR) between the Ti samples and carbon paper was evaluated by a method previously described by Wang et al. [29]. The setup consisted of two pieces of Toray teflon treated carbon paper (TGP-H-090, FuelCellStore, US) sandwiched between the coated samples and two copper sheets. A direct current of $500 \mathrm{~mA}$ was supplied to the copper sheet via a XHR 300-3.5DC power source. The voltage drop across the setup was measured with Tektronix DMM912 digital multimeter while gradually applying compressive forces with a Zwick Roell (Z5KN) ultimate tensile strength machine. The total resistance of the setup was calculated based on Ohm's law with correction made for the resistance of the carbon paper/copper interfaces. $2 \times$ ICR values in which one surface is coated and the other is not are reported for CoBlast treated $\mathrm{Ti}$ while those for bare Ti represent two uncoated sides.

2.4. Electrochemical Characterisation. The electrochemical test setup used for evaluating the corrosion behaviour of the samples consisted of a flat corrosion cell (Princeton Applied Research, K0235, USA) in which the working electrode (coated and uncoated metal samples) was pressed against a Teflon "O" ring exposing $1 \mathrm{~cm}^{2}$ of the working electrode to the electrolyte, $0.5 \mathrm{M} \mathrm{H}_{2} \mathrm{SO}_{4}+2 \mathrm{ppm} \mathrm{HF}$ with $\mathrm{Ag} / \mathrm{AgCl}$ (saturated $\mathrm{KCl}$ ) as reference electrode and platinum mesh as the counter electrode. The setup was connected to a Solartron SI 1287/1255B system comprising a frequency analyser and potentiostat. Potentiodynamic and potentiostatic scans were conducted at ambient temperature and $70^{\circ} \mathrm{C}$, respectively. Prior to and during the polarisation experiments, the electrolyte was bubbled thoroughly with pressurised air to depict the PEM fuel cell cathodic environment while open circuit potential (OCP) was measured for 15 minutes. Potentiodynamic scan was conducted at a scan rate of $1 \mathrm{mV} / \mathrm{s}$ from $-1 \mathrm{~V}$ (versus $\mathrm{OCP}$ ) to $1 \mathrm{~V}$ (versus $\mathrm{Ag} / \mathrm{AgCl}$ ) while potentiostatic scans were conducted for 4 hours at $-0.1 \mathrm{~V}$ and $0.6 \mathrm{~V}$ to simulate the anode and cathode operating conditions, respectively.

\section{Results and Discussion}

3.1. Surface Characterisation. Figure 2 is the $1^{\circ}$ incidence glancing XRD pattern for CoBlast Ti alloy. For reference, the locked coupled scan for the bare alloy is also shown in Figure 2(b). Comparing both patterns, it can be seen that the XRD patterns for Gr-Ti at a relatively low depth of sampling indicates three distinct phases of graphite, alumina (the 




(1) Alumina

(2) Graphite

(3) Titanium

Figure 2: (a) $1^{\circ}$ glancing XRD patterns of CoBlast Ti and (b) locked coupled XRD pattern of bare Ti.

grit material) and titanium. The presence of a pronounced titanium peak at low depth of sampling suggests a thin layer of coating.

The XRD result is corroborated by the XPS spectra shown in Figure 3 in which the superficial layer of the CoBlast treated sample indicates the presence of carbon as graphite at a binding energy of $\sim 284.5 \mathrm{eV}$ (Figure 3(a)) and Ti as elemental titanium and titanium oxide at $\sim 460.1 \mathrm{eV}$ and $\sim 454.7 \mathrm{eV}$, respectively (Figure $3(\mathrm{~b})$ ). The Al2p XPS spectra peak at $74.3 \mathrm{eV}$ in Figure 3(c) is typical of $\mathrm{Al}^{3+}$ oxidation state in alumina while O1s peak at $532 \mathrm{eV}$ is assigned to the nonstoichiometric oxide lattice in alumina [30]. The spectra for bare $\mathrm{Ti}$ are also plotted for comparison in Figure 3 and they indicate the presence of adventitious carbon at $\sim 284.9 \mathrm{eV}$, aluminium at $72.08 \mathrm{eV}$, titanium at $454.08 \mathrm{eV}$ and $460.08 \mathrm{eV}$, and nonstoichiometric oxide of $\mathrm{Ti}$ at $531.28 \mathrm{eV}$. From these results, it is evident that alumina was impregnated on the surface which may not be surprising for a modified grit blasting process.

Figure 4 shows the surface morphology of CoBlast $\mathrm{Ti}$ in the backscattered electron mode indicating the compositional contrast among the constituents on the surface. Based on the EDX analysis combined with the cross-sectional view of the coated surface (Figure 5(a)), it can be deduced that the coated surface consisted of isolated pockets of a carbon rich phase (interpreted as graphite as EDX analysis showed over $90 \% \mathrm{C}$ which is confirmed by the contrast based on atomic number in the BSE mode) and Al-O rich phase with minor carbon content (interpreted as a mixture of alumina and graphite, and also the colour contrast differentiates it from the carbon rich phase) heterogeneously mixed in a Ti-O rich matrix (i.e. the substrate layer) which is consistent with the XRD and XPS results.

Comparing our results with those obtained with hydroxyapatite coatings deposited under similar conditions wherein dense and continuous coating in the range of $\sim 7 \mu \mathrm{m}$ with no significant take-up of the grit material was reported [26], it is obvious that the composition, morphology, and mechanism of formation of graphite coatings on the same substrate differ significantly. The reason for this is not clear at the moment and is the subject of an ongoing study. For reference, the surface morphology of the bare alloy is presented in Figure 5(b) and it shows a smooth and dense surface unlike the modified surface.

Figures 6(a) and 6(b) displays the water contact angles of CoBlast $\mathrm{Ti}$ and the bare $\mathrm{Ti}$ surfaces respectively. The average contact angle for the CoBlast surface was $99.63^{\circ}$ while that for the bare $\mathrm{Ti}$ was $66.32^{\circ}$ indicating that the former is hydrophobic and the latter hydrophilic. From a practical point of view, the use of bipolar plates with hydrophobic surfaces can prevent water accumulation within the channels and mitigate flooding within the PEM fuel cell stack [31, 32].

3.2. Interfacial Contact Resistance. Figure 7 is a plot of $2 \times$ ICR as a function of compaction pressure for CoBlast $\mathrm{Ti}$ and bare alloy compared with that of graphite, the industry benchmark. In all cases, ICR decreased with increasing compaction pressure due to increasing contact area between the carbon paper and the specimens. It can also be observed that both modified and unmodified $\mathrm{Ti}$ samples exhibited higher contact resistance than graphite while CoBlast $\mathrm{Ti}$ exhibited only a marginal decrease to that of Ti. The marginal reduction in ICR could be attributed to the cumulative effect of the pockets of carbon rich phases as indicated in Figure 4. Also, it is possible that the minor carbon content found in the $\mathrm{Al}-\mathrm{O}$ and $\mathrm{Ti}-\mathrm{O}$ rich phases contributed to the reduction of contact resistance. At typical compaction force of $140 \mathrm{~N} / \mathrm{cm}^{2}$ as shown in Table 1, CoBlast Ti exhibited $\sim 32 \%$ decrease in the ICR of the bare alloy. However, the contact resistance of CoBlast Ti is higher than the targeted ICR value $\left(20 \mathrm{~m} \Omega / \mathrm{cm}^{2}\right)$ and needs to be reduced. Possible ways to reduce ICR of CoBlast Ti include optimising the ratio of the abrasive to the coating material and using electrically conductive abrasive such that even if the abrasive is embedded in the coating 


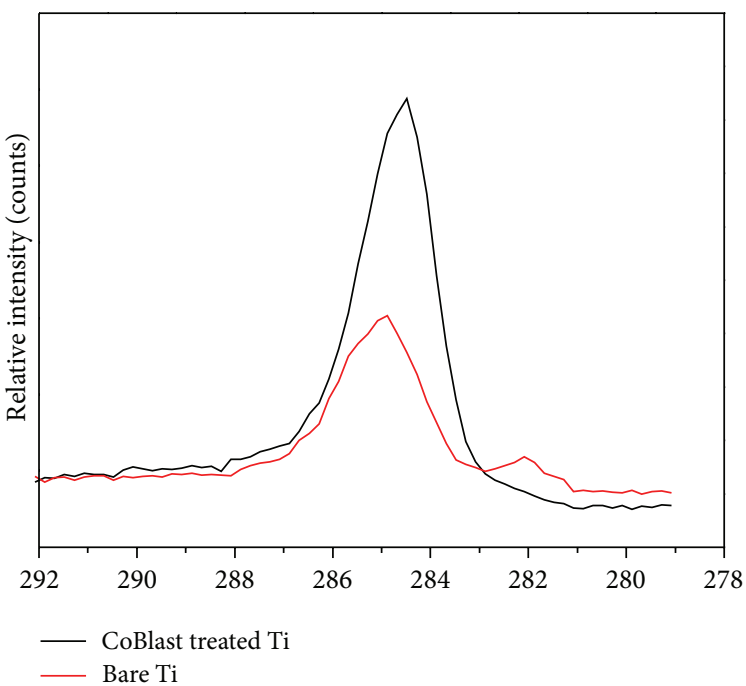

(a)

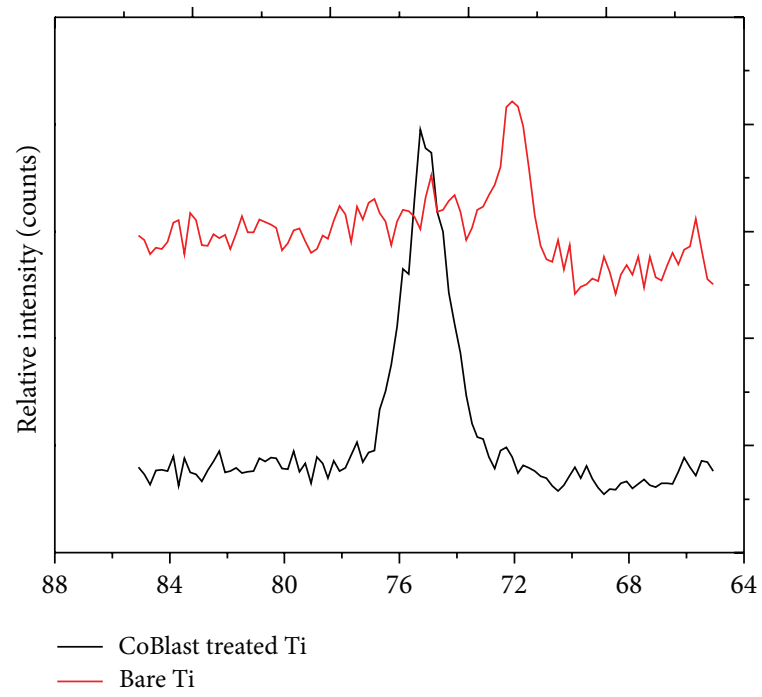

(c)

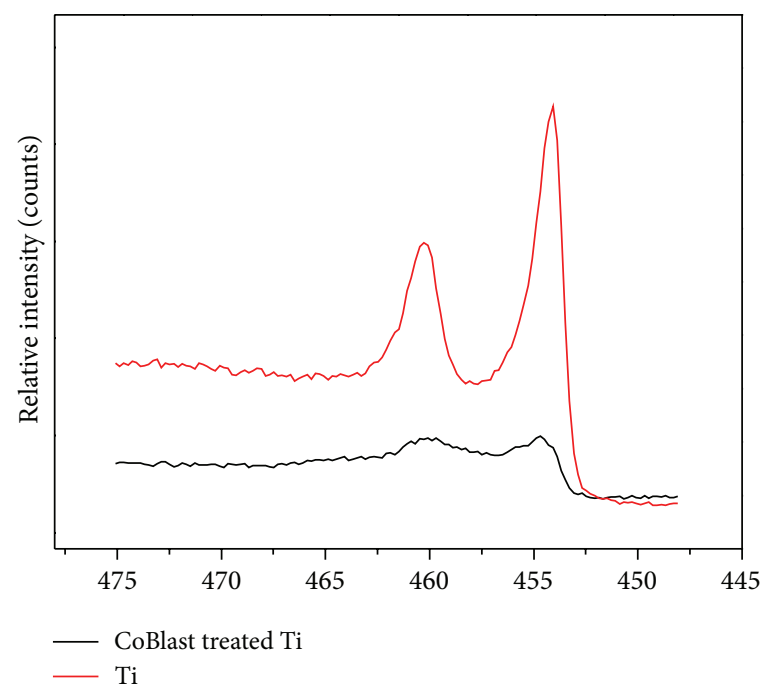

(b)

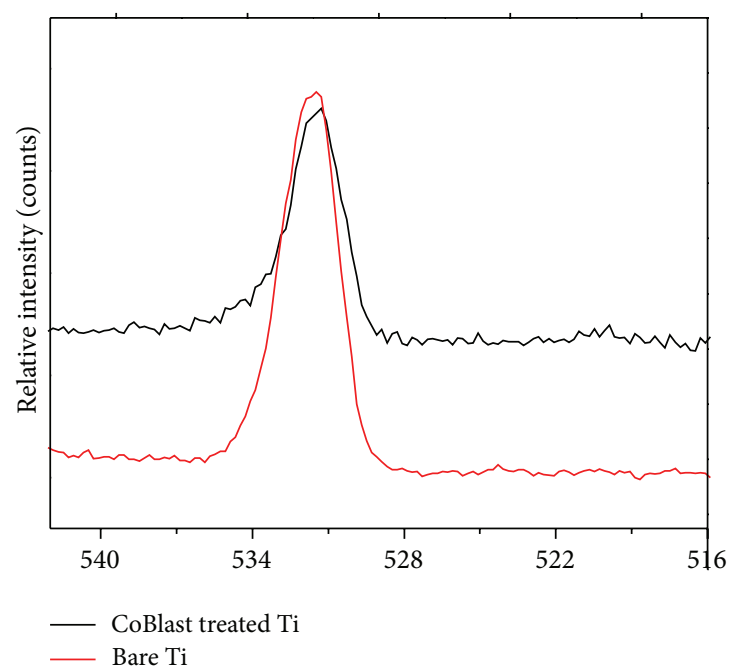

(d)

FIgURE 3: XPS narrow region scan for (a) C1s, (b) Ti2p, (c) Al2p, and (d) O1s for CoBlast Ti and bare Ti.

TABLE 1: $2 \times$ ICR at typical PEM fuel cell compaction force $\left(140 \mathrm{~N} / \mathrm{cm}^{2}\right)$.

\begin{tabular}{lccc}
\hline Material & Graphite & CoBlast treated Ti & Bare Ti \\
\hline ICR $\left(\mathrm{m} \cdot \Omega \mathrm{cm}^{2}\right)$ & 21.19 & 45.70 & 66.50 \\
\hline
\end{tabular}

as seen in the surface morphology of CoBlast Ti, surface conductivity will not be impaired. We are investigating such approaches while also controlling the deposition parameters to improve the continuity and thickness of the coating.

3.3. Electrochemical Polarisation. Figures 8(a) and 8(b) display the potentiodynamic polarisation curve for CoBlast $\mathrm{Ti}$ and bare Ti alloy in simulated PEM fuel cathode $(0.6 \mathrm{~V}$, air purged) and anode $\left(-0.1 \mathrm{~V}, \mathrm{H}_{2}\right.$ gas purged) environments and working potential, respectively.
It can be deduced from the curves that both materials behaved identically in oxidizing and reducing environments indicating that the coatings had negligible influence on the corrosion resistance of the bare metal. In the cathode environment, the corrosion potential of the bare alloy is shifted towards the anodic direction by $350 \mathrm{mV}$. A reverse trend is, however, observed at the anode while no appreciable difference in corrosion current is observed at both electrodes with corrosion currents within $1 \mu \mathrm{A} / \mathrm{cm}^{2}$ range.

Figures 9 and 10 present the potentiostatic polarisation curves for CoBlast $\mathrm{Ti}$ and bare $\mathrm{Ti}$ in simulated cathode and anode PEM fuel cell working conditions. In the cathode environment as shown in Figure 9 CoBlast Ti and bare Ti samples showed an initial decay at the inception of polarisation due to the formation of passive films [27]. CoBlast Ti, however, exhibited a more stable performance than bare Ti reaching a current density of $42 \mu \mathrm{A} \mathrm{cm}^{-2}$ in the first 400 seconds 


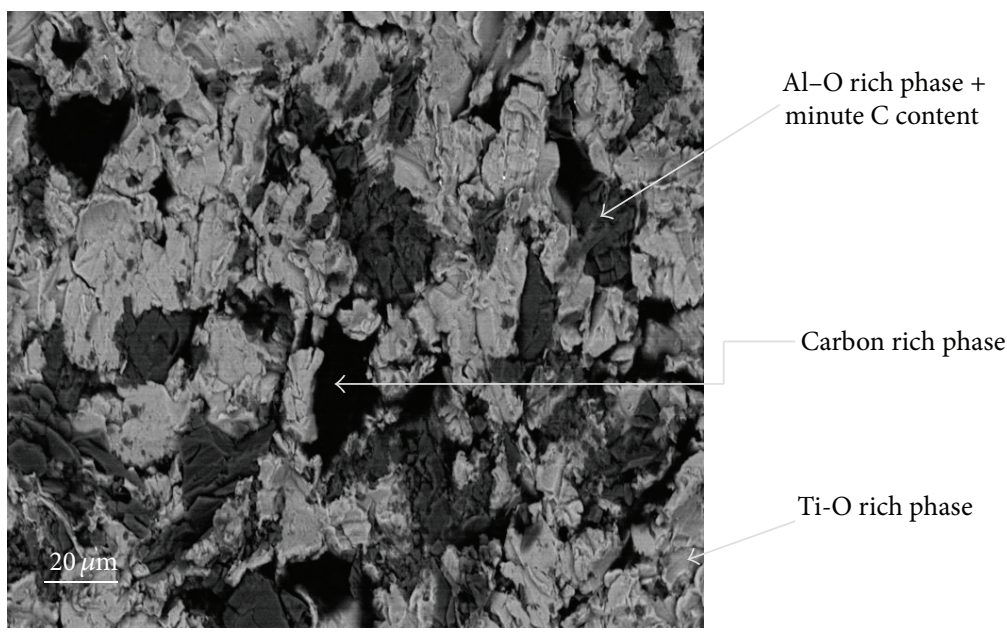

FIGURE 4: SEM/BSD image of CoBlast-Ti showing compositional variation. The darker patches were found to be rich in carbon and the dark grey patches were rich in $\mathrm{Al}$ and $\mathrm{O}$ and had minute $\mathrm{C}$. The lighter grey area were rich in $\mathrm{Ti}$ and oxygen with minute $\mathrm{Al}$ and $\mathrm{C}$.

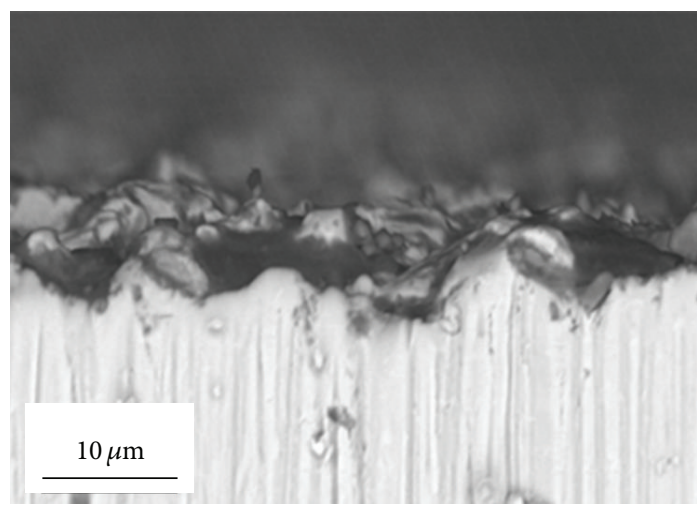

(a)

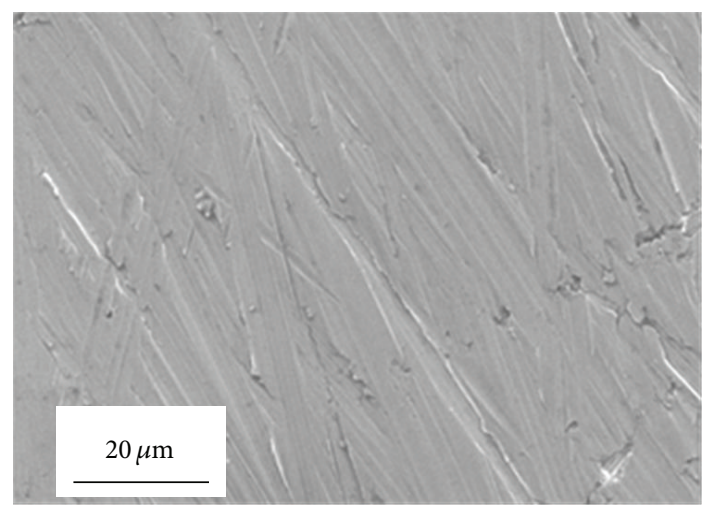

(b)

Figure 5: (a) Cross-sectional image of CoBlast Ti alloy and (b) surface morphology for bare Ti alloy.

and gradually stabilises at $17 \mu \mathrm{A} \mathrm{cm}^{-2}$ while the bare alloy stabilises at $\sim 46 \mu \mathrm{A} \mathrm{cm}^{-2}$. In Figure 10, identical cathodic protection behaviour characterised by negative corrosion currents is observed for CoBlast Ti and bare Ti samples indicating that dissolution rate is reduced. This electrochemical behaviour of modified and bare Ti grade (V) alloy is in agreement with previous studies on other Ti alloys in PEM fuel cell environments and is attributed to the low applied potential of $-0.1 \mathrm{~V}$ which facilitates the formation of a stable oxide layer after an initial dissolution of the preexisting layer $[13,14]$.

In summary, the performance of Gr-Ti in simulated PEM fuel cell environments was unsatisfactory and is due to the discontinuities in the coatings. Such defects in coating would facilitate galvanic corrosion between the coatings and the base metal.

\section{Conclusion}

Investigations into the suitability of CoBlast coated $\mathrm{Ti}$ (V) alloys as PEM fuel cell bipolar plate were reported.
Potentiodynamic polarisation result showed that the coatings exhibited a higher corrosion potential in the cathode environment and a lower potential in anodic environment. No appreciable difference in corrosion currents was observed at both electrodes. Similarly, anodic current in the order of $10^{-5} \mathrm{~A} / \mathrm{cm}^{2}$ range and cathodic current in $-10^{-4} \mathrm{~A} / \mathrm{cm}^{2}$ range were recorded at the cathode and anode, respectively, after 4 hours of potentiostatic polarisation. These results indicate that the coatings did not improve the performance of the bare alloy. The low corrosion resistance of CoBlast modified samples was due to a discontinuous layer of coatings made up of isolated pockets of graphite or alumina mixed with graphite embedded in the substrate oxide layer instead of pure and continuous graphite layer. The defective modified layer also exhibited low surface conductivity with high contact resistance value of $45.7 \mathrm{~m} \Omega \cdot \mathrm{cm}^{2}$ which was slightly lower than that of the bare alloy but twice as high as that of graphite. These results indicated that improvement in the continuity and thickness of the coating is needed for the CoBlast process to be feasible for deposition of graphite 


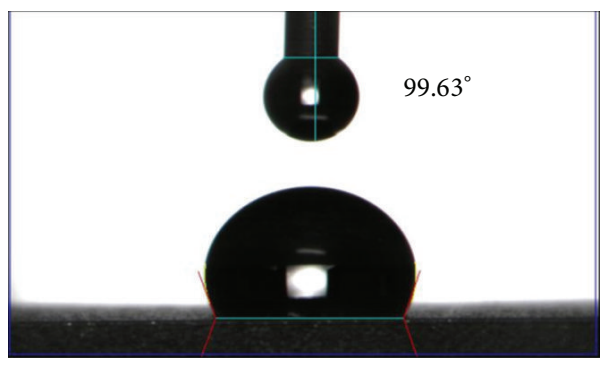

(a)

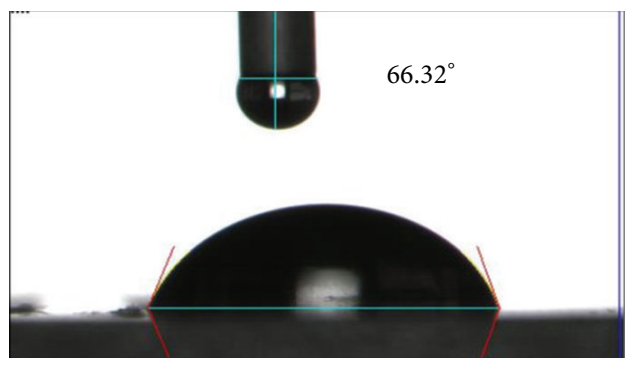

(b)

Figure 6: Water contact angles of (a) CoBlast treated Ti and (b) bare Ti.

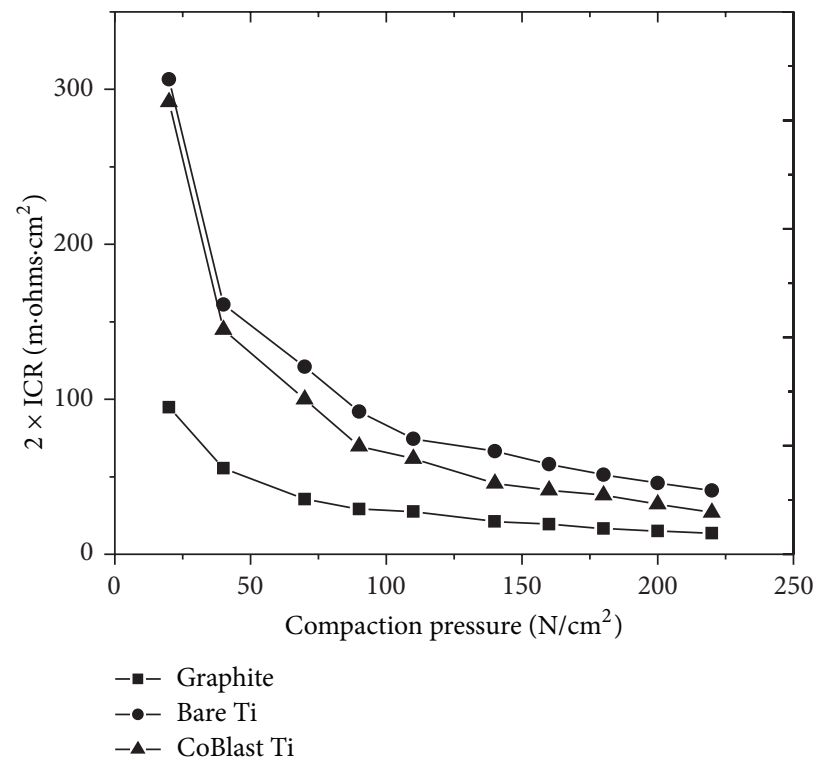

FIGURE 7: Plot of interfacial contact resistance versus compaction pressure for CoBlast $\mathrm{Ti}$, bare Ti, and graphite.

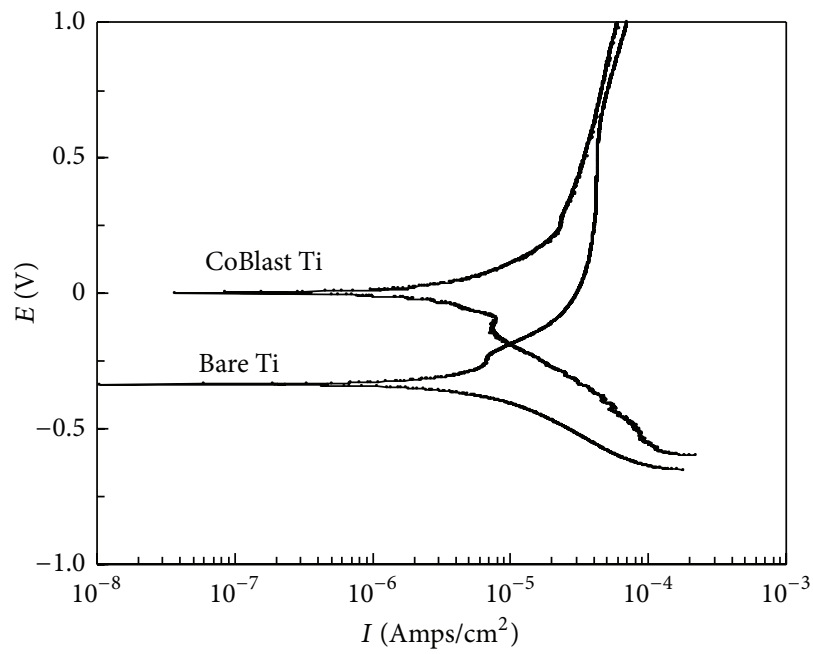

(a)

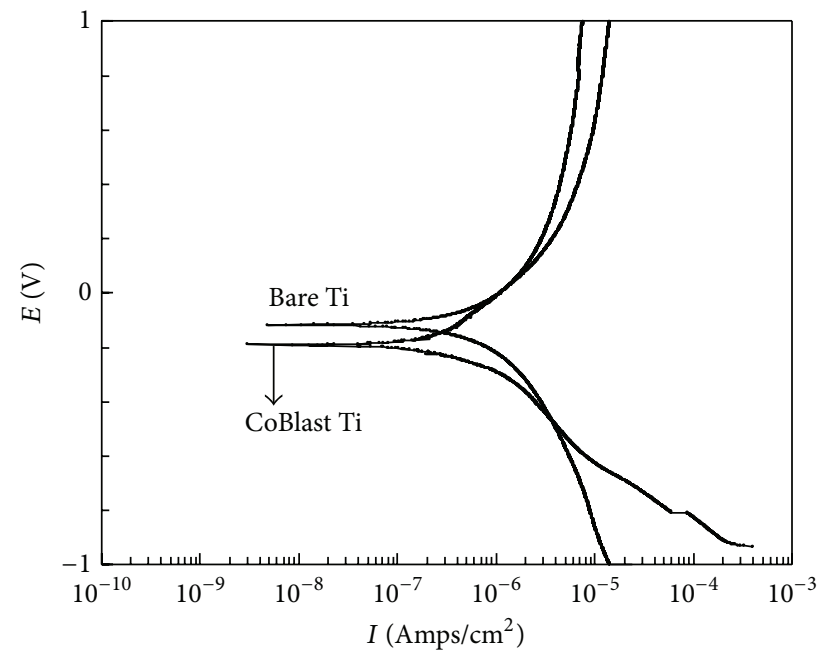

(b)

FIGURE 8: Potentiodynamic polarisation curves for CoBlast Ti and bare Ti in $0.5 \mathrm{MH}_{2} \mathrm{SO}_{4}$ solution with 2 ppm $\mathrm{HF}$ at room temperature in simulated (a) cathode and (b) anode environments. 


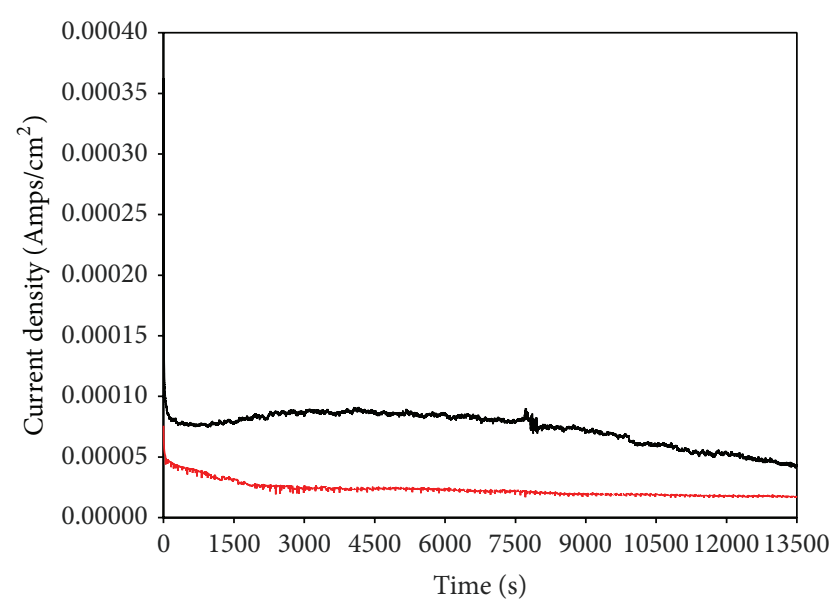

FIgure 9: Potentiostatic polarisation curve for CoBlast Ti (red) and bare $\mathrm{Ti}$ (black) in simulated cathode conditions.

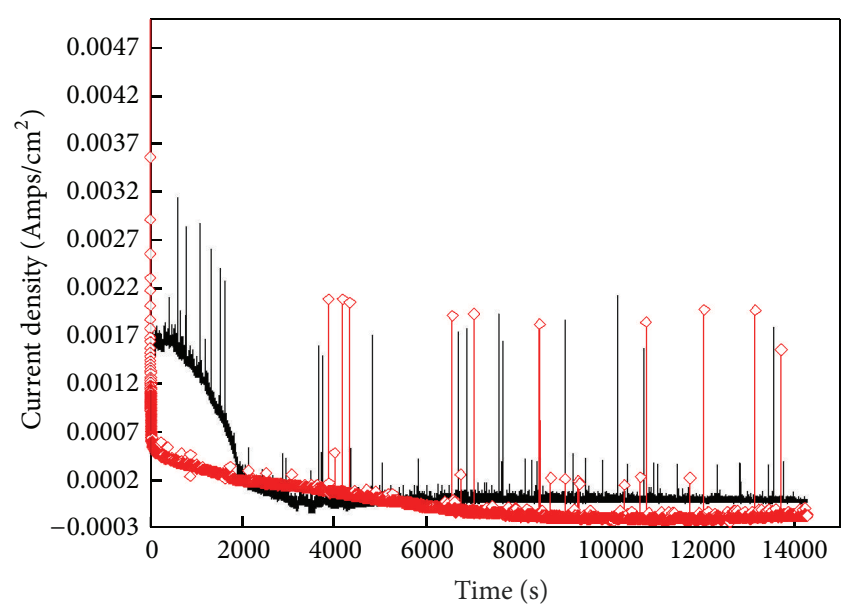

FIgure 10: Potentiostatic polarisation curve for CoBlast Ti (red) and bare Ti (black) in simulated PEM fuel cell anode conditions.

coatings. Hence, research efforts to mitigate these challenges are in progress in our laboratory.

\section{Conflict of Interests}

The authors declare that there is no conflict of interests regarding the publication of this paper.

\section{Acknowledgments}

The authors acknowledge the assistance of the management of the Centre for Research in Engineering Surface Technology (CREST), FOCAS Institute, Dublin Institute of Technology, Dublin 8, especially that of Dr. Brendan Duffy.

\section{References}

[1] A. Appleby, "Fuel cell technology: status and future prospects," Energy, vol. 21, no. 7, pp. 521-653, 1996.
[2] R. G. Reddy, "Fuel cell and hydrogen economy," Journal of Materials Engineering and Performance, vol. 15, no. 4, pp. 474483, 2006.

[3] D. P. Davies, P. L. Adcock, M. Turpin, and S. J. Rowen, "Bipolar plate materials for solid polymer fuel cells," Journal of Applied Electrochemistry, vol. 30, no. 1, pp. 101-105, 2000.

[4] Y. Wang, K. S. Chen, J. Mishler, S. C. Cho, and X. C. Adroher, "A review of polymer electrolyte membrane fuel cells: technology, applications, and needs on fundamental research," Applied Energy, vol. 88, no. 4, pp. 981-1007, 2011.

[5] D. J. L. Brett and N. P. Brandon, "Review of materials and characterization methods for polymer electrolyte fuel cell flowfield plates," Journal of Fuel Cell Science and Technology, vol. 4, no. 1, pp. 29-44, 2007.

[6] R. A. Antunes, M. C. L. Oliveira, G. Ett, and V. Ett, "Corrosion of metal bipolar plates for PEM fuel cells: a review," International Journal of Hydrogen Energy, vol. 35, no. 8, pp. 3632-3647, 2010.

[7] H. Tsuchiya and O. Kobayashi, "Mass production cost of PEM fuel cell by learning curve," International Journal of Hydrogen Energy, vol. 29, no. 10, pp. 985-990, 2004.

[8] I. Bar-On, R. Kirchain, and R. Roth, "Technical cost analysis for PEM fuel cells," Journal of Power Sources, vol. 109, no. 1, pp. 7175, 2002.

[9] B. D. James, J. A. Kalinoski, and K. N. Baum, Massproduction Cost Estimation for Direct $\mathrm{H}_{2}$ PEM Fuel Cell Systems for Automotive Applications: 2010 Update, Directed Technologies, Arlington, Va, USA, 2010.

[10] S. Karimi, N. Fraser, B. Roberts, and F. R. Foulkes, "A review of metallic bipolar plates for proton exchange membrane fuel cells: materials and fabrication methods," Advances in Materials Science and Engineering, vol. 2012, Article ID 828070, 22 pages, 2012.

[11] R. Boyer, G. Welsch, and E. W. Collings, Materials Properties Handbook: Titanium Alloys, The American Society for Metals International, Materials Park, Ohio, USA, 1994.

[12] D. R. Hodgson, B. May, P. L. Adcock, and D. P. Davies, "New lightweight bipolar plate system for polymer electrolyte membrane fuel cells," Journal of Power Sources, vol. 96, no. 1, pp. 233-235, 2001.

[13] Y. Soma, I. Muto, and N. Hara, "Electrochemical properties of titanium in PEFC bipolar plate environments," Materials Transactions, vol. 51, no. 5, pp. 939-947, 2010.

[14] Y. Wang and D. Northwood, "An investigation of commercial grade 2 titanium as a bipolar plate material for PEM fuel cells," Transactions of the American Electrochemical Society, vol. 11, no. 18, pp. 53-60, 2008.

[15] S.-H. Wang, J. Peng, and W.-B. Lui, "Surface modification and development of titanium bipolar plates for PEM fuel cells," Journal of Power Sources, vol. 160, no. 1, pp. 485-489, 2006.

[16] S.-H. Wang, J. Peng, W.-B. Lui, and J.-S. Zhang, "Performance of the gold-plated titanium bipolar plates for the light weight PEM fuel cells," Journal of Power Sources, vol. 162, no. 1, pp. 486-491, 2006.

[17] H.-Y. Jung, S.-Y. Huang, and B. N. Popov, "High-durability titanium bipolar plate modified by electrochemical deposition of platinum for unitized regenerative fuel cell (URFC)," Journal of Power Sources, vol. 195, no. 7, pp. 1950-1956, 2010.

[18] H.-Y. Jung, S.-Y. Huang, P. Ganesan, and B. N. Popov, "Performance of gold-coated titanium bipolar plates in unitized regenerative fuel cell operation," Journal of Power Sources, vol. 194, no. 2, pp. 972-975, 2009. 
[19] D. Zhang, L. Duan, L. Guo et al., "TiN-coated titanium as the bipolar plate for PEMFC by multi-arc ion plating," International Journal of Hydrogen Energy, vol. 36, no. 15, pp. 9155-9161, 2011.

[20] Z. Ren, D. Zhang, and Z. Wang, "Stacks with TiN/titanium as the bipolar plate for PEMFCs," Energy, vol. 48, no. 1, pp. 577-581, 2012.

[21] K. Feng, D. T. K. Kwok, D. Liu, Z. Li, X. Cai, and P. K. Chu, "Nitrogen plasma-implanted titanium as bipolar plates in polymer electrolyte membrane fuel cells," Journal of Power Sources, vol. 195, no. 19, pp. 6798-6804, 2010.

[22] J. Liu, F. Chen, Y. Chen, and D. Zhang, "Plasma nitrided titanium as a bipolar plate for proton exchange membrane fuel cell," Journal of Power Sources, vol. 187, no. 2, pp. 500-504, 2009.

[23] Y. Show, "Electrically conductive amorphous carbon coating on metal bipolar plates for PEFC," Surface and Coatings Technology, vol. 202, no. 4-7, pp. 1252-1255, 2007.

[24] Y. Show, M. Miki, and T. Nakamura, "Increased in output power from fuel cell used metal bipolar plate coated with a-C film," Diamond and Related Materials, vol. 16, no. 4-7, pp. 1159-1161, 2007.

[25] J.-T. Wang, W.-W. Wang, C. Wang, and Z.-Q. Mao, “Corrosion behavior of three bipolar plate materials in simulated SPE water electrolysis environment," International Journal of Hydrogen Energy, vol. 37, no. 17, pp. 12069-12073, 2012.

[26] L. O’Neill, C. O’Sullivan, P. O’Hare, L. Sexton, F. Keady, and J. O'Donoghue, "Deposition of substituted apatites onto titanium surfaces using a novel blasting process," Surface and Coatings Technology, vol. 204, no. 4, pp. 484-488, 2009.

[27] C. O'Sullivan, P. O’Hare, N. D. O'Leary et al., "Deposition of substituted apatites with anticolonizing properties onto titanium surfaces using a novel blasting process," Journal of Biomedical Materials Research-B Applied Biomaterials, vol. 95, no. 1, pp. 141-149, 2010.

[28] P. O’Hare, B. J. Meenan, G. A. Burke, G. Byrne, D. Dowling, and J. A. Hunt, "Biological responses to hydroxyapatite surfaces deposited via a co-incident microblasting technique," Biomaterials, vol. 31, no. 3, pp. 515-522, 2010.

[29] H. Wang, M. A. Sweikart, and J. A. Turner, "Stainless steel as bipolar plate material for polymer electrolyte membrane fuel cells," Journal of Power Sources, vol. 115, no. 2, pp. 243-251, 2003.

[30] "NIST X-ray photo spectroscopy database 20 version 4.1," http://srdata.nist.gov/xps/main_search_menu.aspx.

[31] J. Carton, V. Lawlor, A. Olabi, C. Hochenauer, and G. Zauner, "Water droplet accumulation and motion in PEM (Proton Exchange Membrane) fuel cell mini-channels," Energy, vol. 39, no. 1, pp. 63-73, 2012.

[32] A. Taniguchia and K. Yasuda, "Highly water-proof coating of gas flow channels by plasma polymerization for PEM fuel cells," Journal of Power Sources, vol. 141, no. 1, pp. 8-12. 

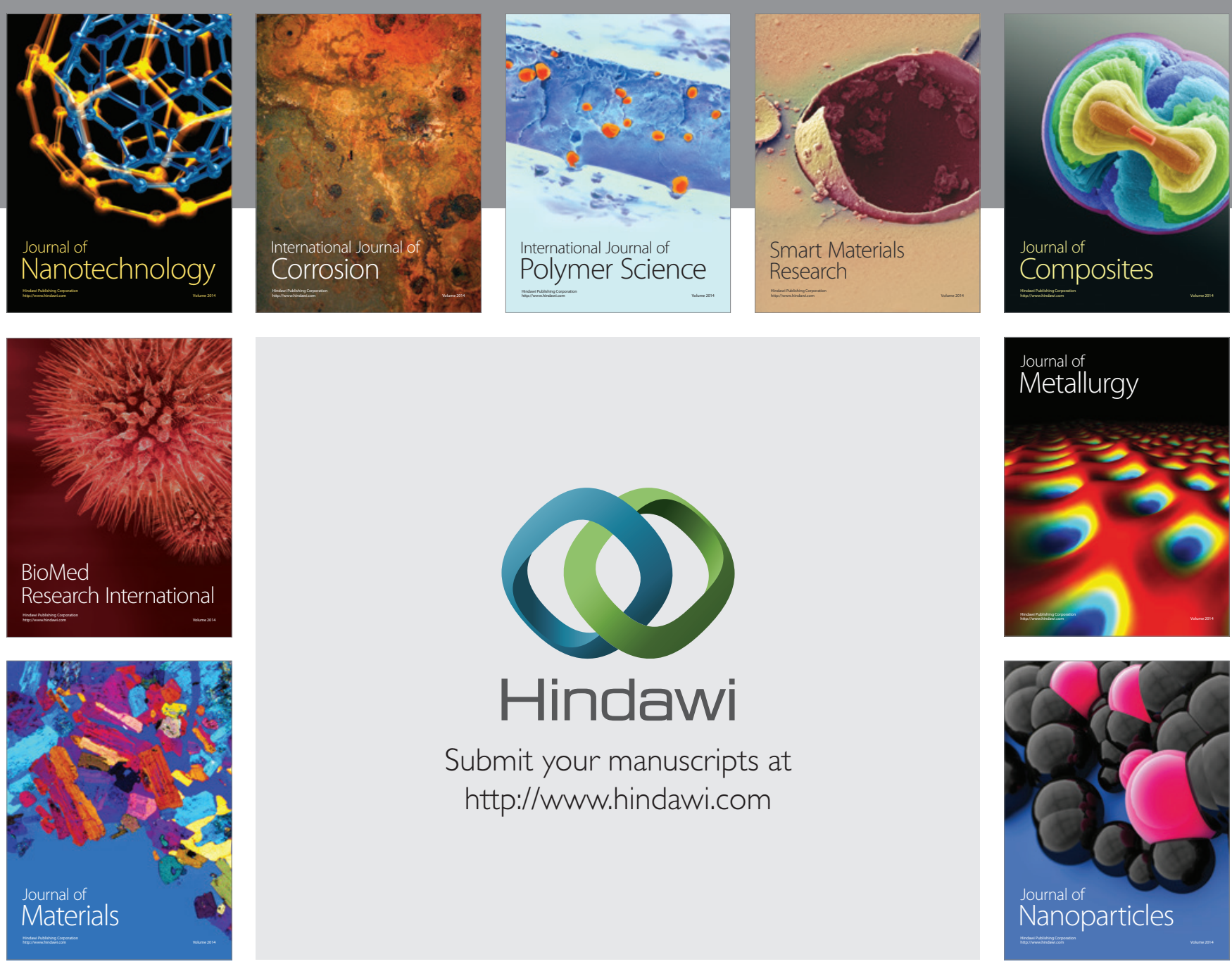

Submit your manuscripts at http://www.hindawi.com
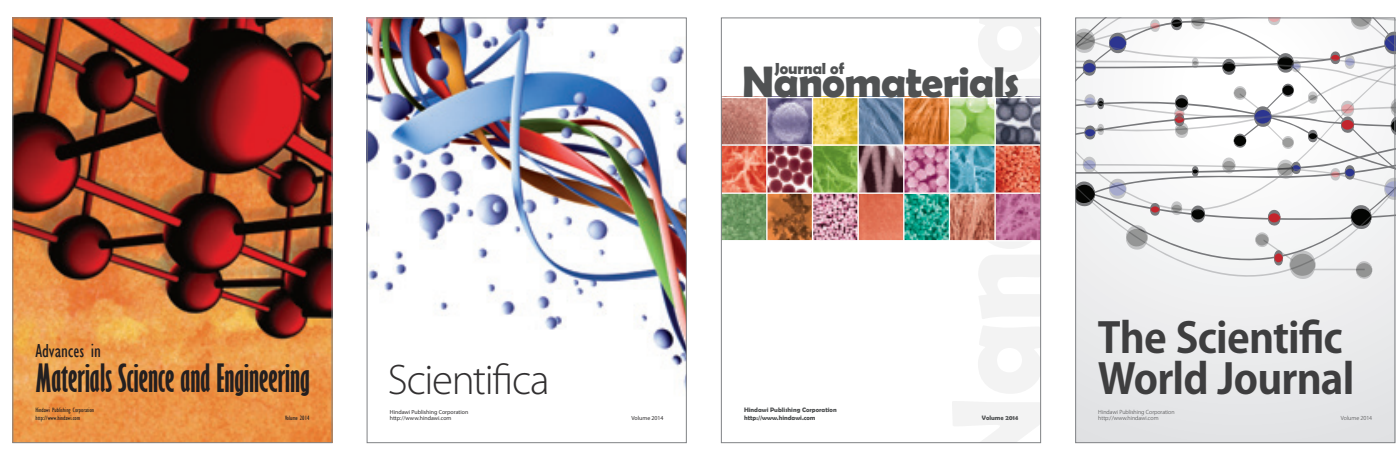

\section{The Scientific World Journal}
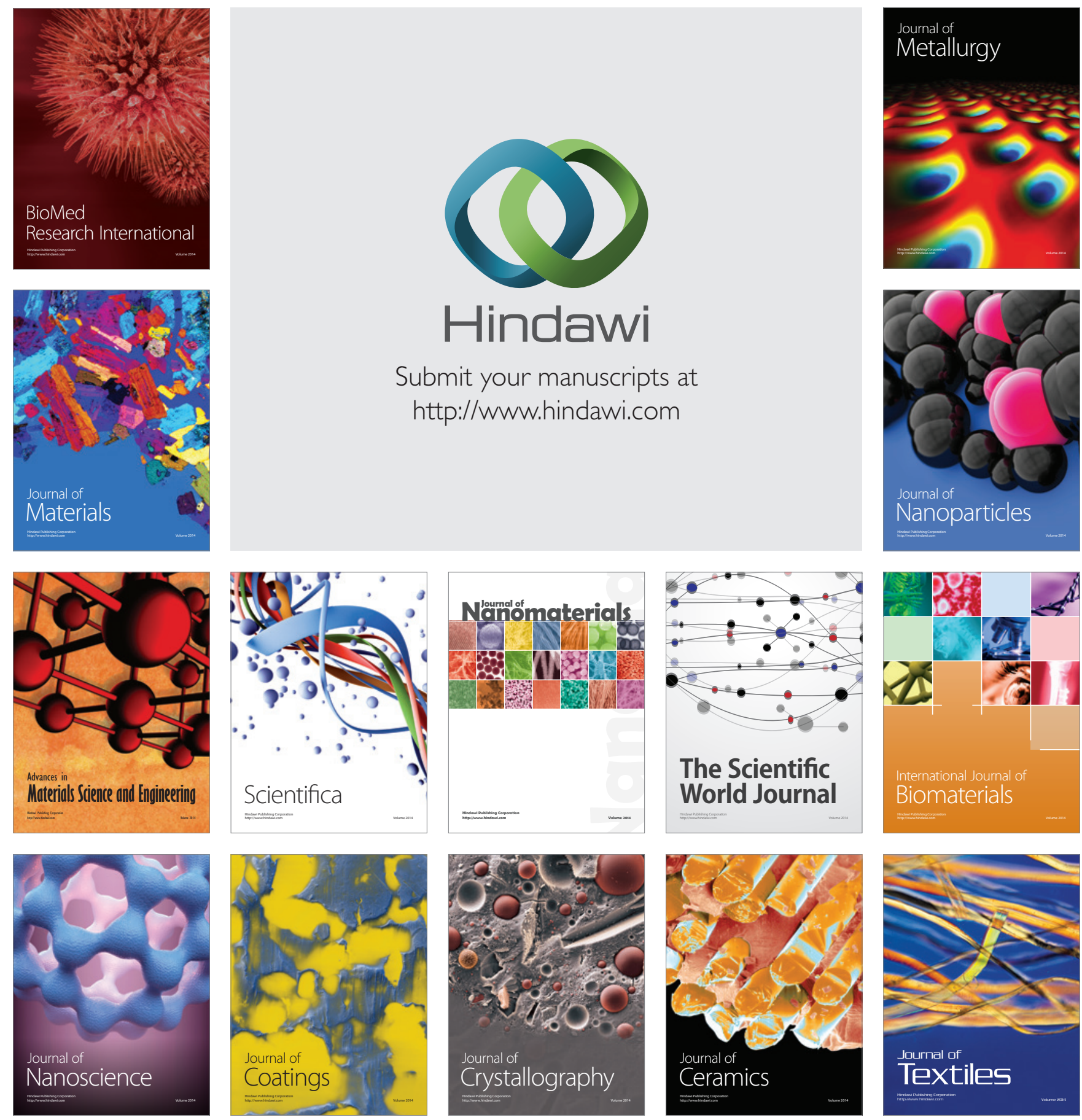